\section{P134 LUNG FUNCTION IN POST-TRANSPLANT HODGKIN'S LYMPHOMA PATIENTS}

doi:10.1136/thx.2010.150987.35

H McConkey, S Sachchithanantham, M Gillion, K Raj, M Kazmi, P Fields, M Streetly, H Milburn. Guys and St. Thomas' NHS Foundation Trust, London, UK

Introduction Pulmonary complications are a prominent cause of morbidity and mortality following stem cell transplant (SCT) accounting for more than $30 \%$ of transplantation-related deaths. Exposure to agents associated with pulmonary toxicity (bleomycin, radiotherapy) is common in patients with Hodgkins lymphoma (HL) for whom SCT is a standard approach at relapse, making them potentially more susceptible to pulmonary toxicity posttransplant. Sequential pulmonary function tests (PFTs), are sensitive measures of lung disease after SCT allowing early diagnosis and treatment, thereby improving outcome. We report a retrospective analysis of serial PFT monitoring of patients with relapsed HL who underwent SCT.

Methods Patients were assessed with serial PFTs pre $(T=0)$ and post SCT (initially 6 weeks and then 3 monthly thereafter). Standardised PFTs were expressed as a percentage of the pretransplant value $(100 \%)$. Tests were carried out by the same personnel, to ensure standardisation and eliminate variability in patient performance.

Results 29 patients were studied with median age at SCT of 35.3 years (range 17.1-60.7 years). Pre-transplant conditioning utilised chemotherapy (predominantly BEAM-carmustine, etoposide, cytarabine, melphalan) for all except two transplants (TBI based). The median follow up was 18 months (range 3-117 months) and a median of four PFTs performed (range 2-16). FEV 1 was decreased $>10 \%$ in $13 / 29$ and $>20 \%$ in five of these patients, FVC was reduced $>10 \%$ in $12 / 29$ and $>20 \%$ in $5 / 29$. TLCO reduction $>10 \%$ was observed in $21 / 29$ and $>20 \%$ in $13 / 29$ and KCO decrease $>10 \%$ occurred in $18 / 29$ and $>20 \% 9 / 29$ patients. Reductions in TLCO/KCO occurred earlier than $\mathrm{FEV}_{1} / \mathrm{FVC}$ reductions (median 1.5 and 3 months respectively). Recovery of lung function occurred in $>50 \%$ of patients who had repeat investigation within $24 \mathrm{~m}$. Significant reduction of TLCO/KCO was observed in only $1 / 10$ patients who had PFTs $>3$ years from transplant (Abstract P134 Figure 1).

Conclusion PFTs initially deteriorated in a significant proportion of patients but tended to recover by $30-40$ months post transplant. This could be due to pulmonary toxicity from conditioning therapy, post-transplant lung injury, or a combination of both. During the first 3 years post-transplant, patients have an increased risk of developing pulmonary complications providing a rationale for serial PFTs.

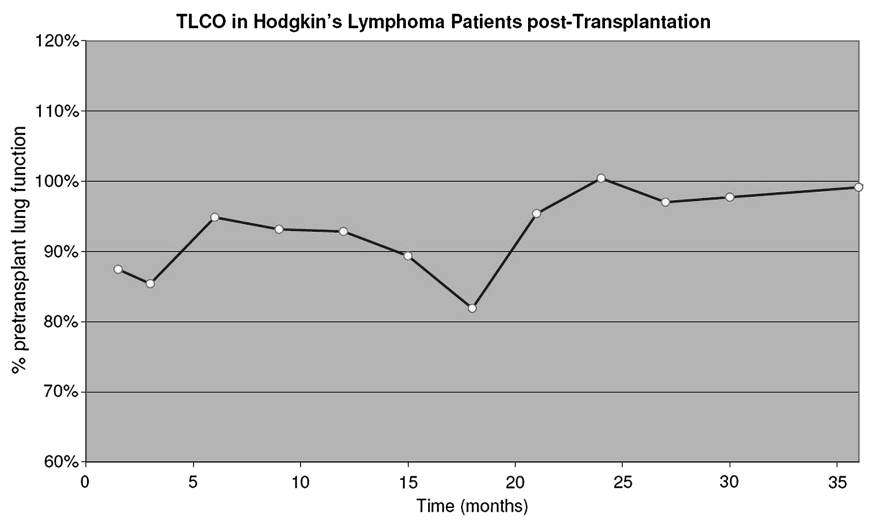

Abstract P134 Figure 1

\section{P135 LUNG FUNCTION IN POST-TRANSPLANT MULTIPLE MYELOMA PATIENTS}

doi:10.1136/thx.2010.150987.36

H McConkey, M Streetly, S Sachchithanantham, M Gillion, M Kazmi, K Raj, H J Milburn. Guys and St. Thomas' NHS Foundation Trust, London, UK

Introduction Chemotherapy followed by autologous stem cell transplant (SCT) is the standard of care for patients with multiple myeloma. However, both conditioning and transplantation increase patient susceptibility to pulmonary complications, a major cause of morbidity and mortality. Pulmonary function tests (PFTs) are routinely performed before and after SCT, providing a means to detect any early decline in pulmonary performance. We report a retrospective analysis of patients undergoing treatment for myeloma at a tertiary London hospital with pre-and post SCT PFTs to assess the impact of transplantation on pulmonary function.

Methods Patients were assessed with serial PFTs pre and post SCT (initially 6 weeks and thereafter 3 monthly). Standardised PFTs were expressed as a percentage of the pre-transplant value (100\%). Tests were carried out by the same personnel, to ensure standardisation and eliminate variability in patient performance.

Results 34 patients with myeloma with median age at SCT of 50 years (range $36-69$ ) were analysed. Conditioning therapy utilised high dose melphalan in 14 and TBI in 18. Median follow-up was 12 months (range 1.5-102) and a median of 4.5 PFTs was performed (range 2-21). $\mathrm{FEV}_{1}$ was reduced by $>10 \%$ in $14 / 34$ and five of these had $>20 \%$. FVC decreased $>10 \%$ in $7 / 34$ and $>20 \%$ in $6 / 34$. TLCO was reduced by $>10 \%$ in $23 / 34$ and $>20 \%$ in $12 / 34$ patients. KCO decreased in 25/34 (>10\%) and 12/34 (>20\%) patients. The median time for maximum reduction was between 2.25 and 4 months for all tests. An improvement in PFT to $>90 \%$ baseline occurred in over $50 \%$ of patients who had repeat investigations and this occurred within 24 months of initial PFT reduction. No significant difference was observed between TBI and melphalan based conditioning approaches.

Conclusion Reductions in $\mathrm{FEV}_{1}$ or $\mathrm{FVC}$ were observed in a minority of patients whereas a majority had a reduction in TLCO/KCO-a significant proportion experiencing $>20 \%$ fall. This reduction occurred early post transplant and improved for many. These changes may reflect possible pulmonary toxicity associated with conditioning therapy, post transplant lung injury or a combination of both and illustrates the necessity for regular prospective monitoring of PFTs following SCT for myeloma.

\section{P136 COMPARISON OF THE ROBD AND THE VENTIMASK METHOD OF PRE-FLIGHT EVALUATION}

doi:10.1136/thx.2010.150987.37

${ }^{1,2}$ S E Martin, ${ }^{1,2} \mathrm{~J} \mathrm{M}$ Bradley, ${ }^{1} \mathrm{~J}$ B Buick, ${ }^{3} \mathrm{~J}$ S Elborn, . 'Belfast Health and Social Care Trust, Belfast, UK; ${ }^{2}$ Health and Rehabilitation Sciences Research Institute, University of Ulster, Jordanstown, UK; ${ }^{3}$ Centre for Infection and Immunity, Queen's University, Belfast, UK

Introduction The Ventimask method of HCT is widely used in clinical practice however; a major limitation of this method is that the gas concentration administered during testing cannot be verified. The Reduced Oxygen Breathing Device (ROBD) is a flight simulator developed by the US military and the inspired fraction of oxygen $\left(\mathrm{FiO}_{2}\right)$ can be accurately determined.

Aim The aim of this study was to compare the results obtained during HCT, in patients with chronic respiratory disease, using the ROBD compared to the Ventimask method. The relationship of $\mathrm{PaO}_{2}$ and $\mathrm{SpO}_{2}$ by both methods was compared to in-flight oxygen saturations. 
Methods Patients with chronic respiratory disease undertook a HCT by the $\mathrm{ROBD}$ and Ventimask methods. The $\mathrm{FiO}_{2}$ was $15.1 \%$ to simulate $8,000 \mathrm{ft}$ which is equivalent to the maximum cabin altitude patients are likely to encounter during commercial air travel.

Results 60 patients, (45 males) with stable chronic obstructive or restrictive respiratory disease participated in the study; age mean (SD) 57 (15) years, $\mathrm{FEV}_{1} 66$ (27)\%, FVC 66 (27)\%, $\mathrm{FEV}_{1} / \mathrm{FVC}$ ratio 60 (18). There was no significant difference between $\mathrm{PaO}_{2}$ preROBD HCT 9.74 (1.19) and pre-Ventimask HCT 9.72 (1.05) paired t-test $\mathrm{p}>0.05 . \mathrm{PaO}_{2}$ measured post-ROBD HCT $(7.36(0.93))$ was significantly lower compared to $\mathrm{PaO}_{2}$ post-Ventimask HCT (7.96 (0.97)) $(p<0.01)$. There was no significant difference in the mean decrease in $\mathrm{SpO}_{2}$ in-flight mean (SD) 6 (3) compared to the mean decrease in $\mathrm{SpO}_{2}$ post-ROBD HCT 5 (3) (p 0.334). In contrast, there was a significant difference in the mean decrease in $\mathrm{SpO}_{2}$ postVentimask HCT 3 (2) compared to the mean decrease in $\mathrm{SpO}_{2}$ inflight and post-ROBD HCT $(\mathrm{p}<0.01)$

Conclusion The ROBD HCT results in a lower $\mathrm{PaO}_{2}$ compared to a Ventimask HCT at a $\mathrm{FiO}_{2}$ of $15.1 \%$. The ROBD assessment more accurately reflected actual changes in $\mathrm{SpO}_{2}$ in-flight and may be a better method of assessment for in-flight oxygen.

\section{Clinical interventions in COPD}

\section{P137 EFFICACY AND SAFETY OF ONCE-DAILY ACLIDINIUM BROMIDE $200 \mu \mathrm{G}$ IN COMBINATION WITH FORMOTEROL IN PATIENTS WITH COPD}

doi:10.1136/thx.2010.150987.38

${ }^{1} \mathrm{P}$ Śliwiński, ${ }^{2} \mathrm{D}-\mathrm{W}$ Perng, ${ }^{3} \mathrm{~A}$ Chuchalin, ${ }^{4} \mathrm{P}$ W Jones. ${ }^{1}$ Institute of Tuberculosis and Lung Diseases, Warsaw, Poland; ${ }^{2}$ Taipei Veterans General Hospital, Taipei, Taiwan; ${ }^{3}$ Pulmonology Research Institute, Moscow, Russia; ${ }^{4}$ St George's, University of London, London, UK

Introduction Combinations of different classes of medication used in the management of chronic obstructive pulmonary disease (COPD) may provide additional improvements compared with monotherapy. This study assessed the efficacy and safety of aclidinium bromide $200 \mu \mathrm{g}$, a novel long-acting muscarinic antagonist, combined with formoterol, a long-acting $\beta$-agonist. All combination and monotherapy treatments were delivered as single inhalations.

Methods 566 patients with moderate to severe COPD were randomised in a double-blind manner to receive aclidinium plus formoterol $6 \mu \mathrm{g} \quad(\mathrm{n}=121), 12 \mu \mathrm{g} \quad(\mathrm{n}=120)$ or $18 \mu \mathrm{g} \quad(\mathrm{n}=125)$, or monotherapy with aclidinium $(n=76)$, formoterol $12 \mu \mathrm{g}(\mathrm{n}=65)$ or placebo $(n=59)$. Treatment was administered once-daily for 4 weeks via the Genuair ${ }^{\circledR}$ inhaler, a multidose dry powder inhaler. The primary efficacy endpoint was change from baseline in normalised forced expiratory volume in 1 second $\left(\mathrm{FEV}_{1}\right)$ area under the curve over $12 \mathrm{~h}\left(\mathrm{AUC}_{0-12 \mathrm{~h}}\right)$ at 4 weeks. Safety was assessed throughout the study.

Results There was a mean $( \pm S E)$ increase from baseline in normalised $\mathrm{FEV}_{1} \mathrm{AUC}_{0-12 \mathrm{~h}}$ at 4 weeks with aclidinium plus formoterol $6, \quad 12$ or $18 \mu \mathrm{g} \quad(0.170 \pm 0.022, \quad 0.219 \pm 0.22$ and $0.230 \pm 0.0221$, respectively), and aclidinium $(0.075 \pm 0.027 \mathrm{l})$ and formoterol $(0.099 \pm 0.031 \mathrm{l})$ monotherapy. No improvement was observed in the placebo group. All combinations were significantly superior to placebo $(\mathrm{p}<0.0001)$ and to both monotherapies $(p<0.001)$, except for the comparison between aclidinium and formoterol $6 \mu \mathrm{g}$ and formoterol $12 \mu \mathrm{g}$ monotherapy. Mean change from baseline in $12-\mathrm{hEV}_{1}$ at 4 weeks is shown in the figure. Aclidinium plus formoterol 6,12 or $18 \mu \mathrm{g}$ was well-tolerated with a safety profile similar to that observed with monotherapy or placebo.
Conclusions Aclidinium combined with formoterol provided greater improvements in pulmonary parameters than either drug alone or placebo. The bronchodilation provided by aclidinium and formoterol $18 \mu \mathrm{g}$ was comparable to aclidinium and formoterol $12 \mu \mathrm{g}$, suggesting the optimal dose of formoterol was $12 \mu \mathrm{g}$. No safety concerns arose during the study. These findings support the combination of aclidinium and formoterol for the treatment of COPD.

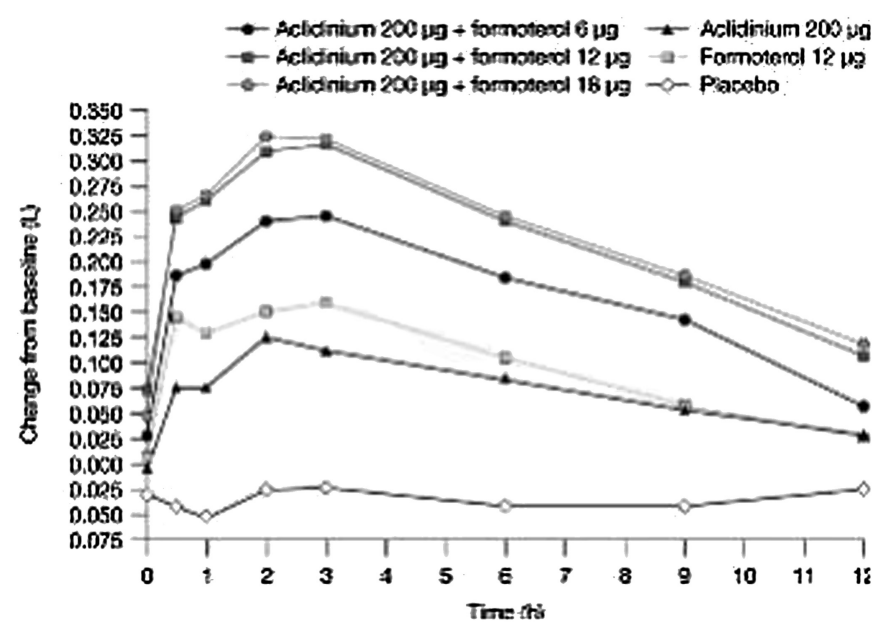

Abstract P137 Figure 1

Funding This study was supported by Almirall S.A., Barcelona, Spain, and Forest Laboratories, Inc., New York, USA.

Genuair $^{\circledR}$ is a registered trademark of Almirall S.A.

\section{P138 EFFICACY OF INHALED PAN-SELECTIN ANTAGONIST BIMOSIAMOSE ON OZONE-INDUCED AIRWAY INFLAMMATION IN HEALTHY SUBJECTS}

doi:10.1136/thx.2010.150987.39

${ }^{1} \mathrm{~A}$ Kirsten, ${ }^{1} \mathrm{H}$ Watz, ${ }^{1} \mathrm{G}$ Kretschmar, ${ }^{1} \mathrm{~F}$ Pedersen, ${ }^{2} \mathrm{~W}$ Meyer-Sabellek, ${ }^{2} \mathrm{D}$ Bock,

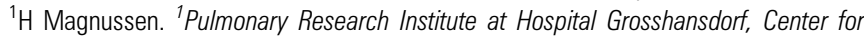
Pneumology and Thoracic Surgery, Grosshansdorf, Germany; ${ }^{2}$ Revotar Biopharmaceuticals AG, Hennigsdorf, Germany

Selectins, a family of adhesion molecules, play a key role in the activation and extravasation of leukocytes in inflammatory diseases, like COPD. We investigated the effect of repeated inhalations of the pan-selectin antagonist Bimosiamose on ozone-induced airway inflammation in healthy volunteers. In a double-blind, placebocontrolled, randomised, cross-over study the effect of a 4-days treatment with $10 \mathrm{mg}$ of Bimosiamose bid inhaled by a breath actuated nebuliser (AKITA2 APIXNEB®) on cellular and noncellular composition of induced sputum after inhalation of ozone $(250 \mathrm{ppb})$ for three hours was evaluated. 18 subjects were randomised and completed the study. All treatments were safe and well tolerated. Bimosiamose, compared to placebo treatment, reduced numbers of sputum neutrophils by $40 \%(p=0.068)$ and lymphocytes by $65 \%(p=0.004)$. Sputum concentration of interleukin- 8 and MMP-9 was diminished by $35 \%(p=0,004)$ and $46 \%(p=0,022)$, respectively. Inhalation of Bimosiamose showed a broad and favourable significant effect on ozone-induced airway inflammation in healthy subjects. Further studies have to proof and translate this anti-inflammatory effect of Bimosiamose into a clinical benefit in patients with COPD. 